\title{
Data report: three-dimensional observation and quantification of internal structure of sediment core from Challenger Mound area in Porcupine Seabight off western Ireland using a medical X-ray $\mathrm{CT}^{1}$
}

Akiko Tanaka ${ }^{2}$ and Tsukasa Nakano ${ }^{2}$

\section{Chapter contents}

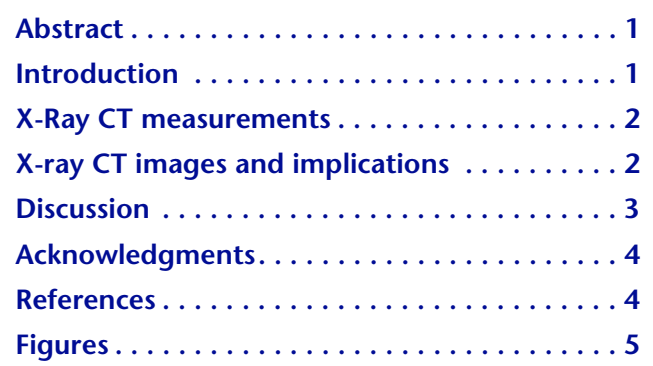

\footnotetext{
${ }^{1}$ Tanaka, A., and Nakano, T., 2009. Data report: three-dimensional observation and quantification of internal structure of sediment core from Challenger Mound area in the Porcupine Seabight off western Ireland using a medical X-ray CT. In Ferdelman, T.G., Kano, A., Williams, T., Henriet, J.-P., and the Expedition 307 Scientists, Proc. IODP, 307: Washington, DC (Integrated Ocean Drilling Program Management International, Inc.). doi:10.2204/iodp.proc.307.209.2009 ${ }^{2}$ Geological Survey of Japan, AIST, Tsukuba Central 7, 1-1-1 Higashi, Tsukuba 305-8567, Japan. Correspondence author: akiko-tanaka@aist.go.jp
}

\begin{abstract}
Three sites on and near Challenger Mound, a carbonate mound structure covered with dead deepwater coral rubble in Porcupine Seabight on the southwest Irish continental margin, were drilled during Integrated Ocean Drilling Program Expedition 307 in May 2005. In addition to the mound, one site immediately downslope of Challenger Mound and an upslope site were drilled to constrain the stratigraphic framework of the slope/mound system and to identify and correlate erosional surfaces. X-ray computerized tomography (CT) was used to image $6 \mathrm{~m}$ long half-round cores recovered from an off-mound site. X-ray CT visualizes threedimensional (3-D) distribution of X-ray linear absorption coefficients of samples and allows examination of 3-D measurements of complex shapes of corals fragments and dropstones in sedimentary sequences.
\end{abstract}

\section{Introduction}

During Integrated Ocean Drilling Program (IODP) Expedition 307, three sites were drilled on Challenger Mound in Porcupine Seabight off western Ireland in May 2005 (see the "Expedition 307 summary" chapter). The aim of this expedition was to understand the origin and evolution of the coldwater coral banks in Porcupine Seabight, one of the most intensively studied provinces. In addition to the mound, one site immediately downslope of Challenger Mound and an upslope site were drilled. The mound roots on a strongly erosive unconformity and is seated partly on an enigmatic sequence of sigmoidal units and partly on a semitransparent layer. Eleven holes with a maximum depth of $270 \mathrm{~m}$ were drilled on and near Challenger Mound, and core sections penetrating a thick coral reef body were recovered. The mound itself consists of a repetition of floatstone and rudstone that rests on a sharp erosional boundary and contains coral (Lopheria pertusa) fragments, other bioclasts, a fine-grained clay matrix, and calcareous nannofossils (see the "Expedition 307 summary" chapter).

Through the Ocean Drilling Program (ODP) and IODP, some attempts have been made to evaluate $\mathrm{X}$-ray imaging for observation and description of core samples with a computerized tomography 
(CT) scanner (e.g., Iturrino et al., 2004; Shirai et al., 2007). In this paper, we describe and discuss the use of medical X-ray CT to map coral fragments within host sediments. X-ray CT generates X-ray images along freely chosen sections and offers the possibility of density measurements based on X-ray attenuation. X-ray CT was performed using the archive-half section of core sample from Hole U1316A. Site U1316 is located in downslope sediment deposits $\sim 700 \mathrm{~m}$ southwest of Challenger Mound. The threedimensional (3-D) X-ray CT images were compared with split-surface digital images of the correlative half core. This paper confirms that X-ray CT is a powerful tool for core observation because it is nondestructive and provides rapid 3-D imaging.

\section{X-ray CT measurements}

$\mathrm{X}$-ray CT is a radiological imaging system first developed by Hounsfield (1973). X-ray CT is a technique to reconstruct a CT image showing the spatial distribution of X-ray linear absorption coefficients of samples. This technique allows us to observe and nondestructively analyze 3-D internal structures. Linear absorption coefficient depends on density and chemical composition of samples and X-ray energy used. Higher density and higher atomic numbers result in higher attenuation of X-rays. X-ray CT produces images in which grayscale intensity corresponds to the X-ray linear attenuation coefficient. Individual CT images are referred to as slices. By acquiring a contiguous set of slices, data for a complete volume can be obtained.

A medical X-ray CT scanner (Hitachi CT-W2000) at Geological Survey of Japan, AIST, was used to acquire the CT images. The medical CT system was originally designed for use on human subjects to image soft tissue and bone. Therefore, medical CT systems are required to use a limited dose of relatively low energy $\mathrm{X}$-rays to minimize patient exposure. Cores used in this study consist mainly of sediments with densities of $\sim 2 \mathrm{~g} / \mathrm{cm}^{3}$, which is consistent with that of human bone. It might be reasonable to use medical X-ray for 3-D mapping of corals within bulk sediments.

All samples were scanned with an X-ray peak energy of $120 \mathrm{kV}$ with $150 \mathrm{~mA}$ current. Slice acquisition times were $4 \mathrm{~s}$ per scan. A $160 \mathrm{~mm}$ field of reconstruction was captured in a 512 pixel $\times 512$ pixel image. The resolution of CT scanning is $0.313 \mathrm{~mm} /$ pixel $\times 0.313 \mathrm{~mm} /$ pixel. Contiguous two-dimensional 16-bit CT images at intervals of $1 \mathrm{~mm}$ sequentially from core top to core bottom of each half-round core were acquired. These data were used to reconstruct the 3-D images. Grayscale images from X-ray CT scanning were constructed using histogram equaliza- tion using the lower limit value of water, which provides contrastive images for structure observations.

\section{$\mathrm{X}$-ray $\mathrm{CT}$ images and implications}

Half-round cores from Hole U1316A with a total length $\sim 6 \mathrm{~m}$ (Sections 307-U1316A-6H-4, $0 \mathrm{~cm}$, through $7 \mathrm{H}-1,54.5 \mathrm{~cm}$ ) were subjected to X-ray CT analysis. To save measurement time, X-ray CT measurements were performed with several cores mounted on the stage at the same time divided by boards and styrene foam (Fig. F1). Total data acquisition time with sample preparation was $\sim 10 \mathrm{~h}$ for these samples. After the CT data were taken, cores were sent back to the Bremen Core Repository for further studies in the future. The obtained raw X-ray CT slice image contains several pieces of information (Fig. F2). Core data were extracted from this raw data. An example of a set of slices of X-ray CT images is shown in Figure F3.

The intensity of the transmitted X-ray beam is usually expressed as CT number (Hounsfield, 1973), which is the ratio of the linear attenuation coefficient of the material to that of pure water. Histograms clearly show significant difference in CT numbers among air, board, liner, water, sediments, and pebbles (Fig. F4A). Figure F4B is a close-up of a histogram to enhance distribution of denser materials.

Images on the $y-z$ and $x-z$ planes, as defined in Figure F5, are shown in Figure F6, although any angle could be displayed. The stage stroke of the X-ray CT system prohibits measuring $1.5 \mathrm{~m}$ long whole sections at the same time, which results in the same section measurements being divided by two. A distortion with increasing distance from the horizontal plane during X-ray CT measurements occurs, which is most readily observed as a misfit between adjacent sets of slices. Therefore, Sections 307-U1316A-4H-4, $4 \mathrm{H}-5$, and $4 \mathrm{H}-6$ are shown in two parts, which overlap by a few centimeters.

These images are mainly compared with digital images of the split surface, which shows good correlation on the basis of cracks, lithological boundaries, and sedimentary structures. Sedimentary structures, such as various types of lamination and shape, occurrence, and textural relation to surrounding host sediments of dropstones and pebbles, are easily recognized on X-ray CT images. Since X-ray CT numbers eventually depend on the density of a substance and densities of coral-bearing and surrounding sediments are nearly the same, coral fragments would not be well distinguished from surrounding sediments on X-ray CT images. Carbonate cementation 
may render density distributions that reflect sedimentary structures as homogeneous, preventing clear imaging of these sedimentary structures. It may also relate to resolution of the X-ray image. On the other hand, X-ray images can reveal sedimentary and postsedimentation structures and materials that cannot be seen on the split core surface.

Cracks have widened since the core photos were taken. It is notable that some cracks seen in the Xray CT images were not clear on core photos. This means that cracks formed and grew with time, especially in coral-bearing layers. Drilling disturbances close to the liners were frequently observed.

\section{Section 307-U1316A-6H-4}

This section is shown in Figure F6A, F6B, and F6C. The upper $20 \mathrm{~cm}$ of this section consists of brown silty clay, which can be recognized on X-ray CT images. This section also contains the boundary between lithologic Subunits $2 \mathrm{~A}$ and $2 \mathrm{~B}$ as shown by the yellow dashed line in Figure F6A and F6B. Subunit $2 \mathrm{~A}$ is dominated by siliciclastic fine to medium sands, whereas corals predominate in Subunit 2B. However, densities of coral-bearing layers and surrounding sediments are similar, which prevents clear discrimination on X-ray CT images. X-ray CT images clearly map dropstones, and some appear in the core photo within Subunit 2A. In the lower part of this section, a dense rudstone rich in highly fragmented corals is observed.

\section{Section 307-U1316A-6H-5}

This section is shown in Figure F7A, F7B, and F7C. In the upper part of this section, from 0 to $13 \mathrm{~cm}$, a dense rudstone rich in highly fragmented corals is recognized on X-ray CT images. Corals occur in distinct layers interbedded with siliciclastic sediments, also seen clearly in X-ray CT images.

\section{Section 307-U1316A-6H-6}

This section is shown in Figure F8A, F8B, and F8C. Several dropstones/pebbles (at $67 \mathrm{~cm}$ in Fig. F8A, F8B) clearly captured in X-ray CT images cannot be seen on the split core surface. Some sedimentary structures and drilling disturbances are evident in Xray CT images.

\section{Section 307-U1316A-6H-7}

This section consists of $L$. pertusa rudstone with silty clay matrix (see the "Expedition 307 summary" chapter). The X-ray CT image clearly captures one pebble/dropstone (at $52 \mathrm{~cm}$ in Fig. F9) and its relationship to the surrounding host sediments.

\section{Section 307-U1316A-6H-CC}

This section (Fig. F10) consists of $L$. pertusa rudstone with silty clay matrix (see the "Expedition 307 summary" chapter). X-ray CT images suggest that cracks divided this section into four segments and lower density material appears below these cracks.

\section{Section 307-U1316A-7H-1}

At the top of this section (Fig. F11), the core photo shows pebbles with diameters from 0.5 to $2 \mathrm{~cm}$, which are also observed in CT images. A histogram of CT numbers shows that this section contains denser materials (Fig. F4A, F4B). This information from X-ray CT images is consistent with the core photo. The CT image shows a major unconformity located between lithologic Units 2 and 3. Also, the CT image clearly distinguishes the uppermost $10 \mathrm{~cm}$ of Subunit 3A, which shows gradual change from light gray to greenish gray. Below this level, the subunit is characterized by generally homogeneous sediments (see the "Expedition 307 summary" chapter).

\section{Discussion}

X-ray CT has proven to be a relatively quick method to reveal 3-D internal structures of core samples and 3-D distribution of coral fragments, dropstones, and pebbles and their relationship to the surrounding host sediments without any disturbance to samples. CT scanning immediately after coring and before splitting may be efficient to avoid degradation of cores.

Sedimentary and coring structures are clearly recognized in X-ray CT images (see $20-90 \mathrm{~cm}$ in Fig. F6A, F6B), implying that these structures retain density contrasts. X-ray imaging is also efficient for observing dropstones and pebbles. However, Shirai et al. (2007) suggested that carbonate rocks might be unsuitable for X-ray imaging because cementation often obscures density contrasts, rendering sedimentary structures homogeneous. When CT numbers are selected in narrower ranges, which is more suitable for observation of sedimentary structures, coral fragments can be clearly distinguished on CT images (Fig. F12).

Changes in point of view are conspicuous in some features. Ashi (1997) and Shirai et al. (2007) suggest that some lamina sets drastically change in visibility according to changes in observation direction. 3-D imaging with an X-ray CT system can be observed from any angle. Figure F12 shows the 3-D distribution of CT numbers of Section 307-U1316A-7H-1 (Fig. F11) from the viewpoint at an azimuth of $210^{\circ}$ 
and elevation of $60^{\circ}$. Once X-ray CT data are obtained, such a representation is easily available.

Information on X-ray CT images, coupled with shipboard measurements, is useful to estimate some physical properties. For example, Ashi (1997) obtained 3-D density distributions on unsplit cores using a medical X-ray CT scanner. The same method is possible using data obtained in this study and may give a spatially precise map of density variation in the core compared with GRA density profile and magnetic susceptibility at $5 \mathrm{~cm}$ intervals (Fig. F13).

Effective and efficient use of the X-ray CT system represents the possibility for rapid systematic characterization of 3-D structural features and may improve subsampling and core processing procedures.

\section{Acknowledgments}

We thank the IODP and Transocean crews of the JOIDES Resolution of Expedition 307. Samples were provided by the Integrated Ocean Drilling Program (IODP). Walter Hale of the Bremen Core Repository kindly sent us the samples. Juichiro Ashi provided helpful reviews. Ken Ikehara and Yoshito Nakashima are kindly thanked for their technical assistance during X-ray CT data collection. Figures F4 and F13 were produced with Generic Mapping Tools (Wessel and Smith, 1998).

\section{References}

Ashi, J., 1997. Computed tomography scan image analysis of sediments. In Shipley, T.H., Ogawa, Y., Blum, P., and Bahr, J.M. (Eds.), Proc. ODP, Sci. Results, 156: College Station, TX (Ocean Drilling Program), 151-159. doi:10.2973/odp.proc.sr.156.019.1997

Hounsfield, G.N., 1973. Computerized transverse axial scanning (tomography), Part I. Description of system. Br. J. Radiol., 46:1016-1022.

Iturrino, G.J., Ketcham, R.A., Christiansen, L., and Boitnott, G., 2004. Data report: permeability, resistivity, and $\mathrm{X}$-ray computed tomography measurements in samples from the PACMANUS hydrothermal system. In Barriga, F.J.A.S., Binns, R.A., Miller, D.J., and Herzig, P.M. (Eds.), Proc. ODP, Sci. Results, 193: College Station, TX (Ocean Drilling Program), 1-14. doi:10.2973/ odp.proc.sr.193.205.2004

Shirai, M., Nishimura, M., and Yasuda, H., 2007. Data report: descriptive evaluation of consolidated sedimentary rock structures with X-ray imaging: examples from Site 1276 core samples. In Tucholke, B.E., Sibuet, J.- C., and Klaus, A. (Eds.), Proc. ODP, Sci. Results, 210, College Station, TX (Ocean Drilling Program), 1-21. doi:10.2973/odp.proc.sr.210.111.2007

Wessel, P., and Smith, W.H.F., 1998. New, improved version of the Generic Mapping Tools released. Eos, Trans. Am. Geophys. Union, 79:579. doi:10.1029/98E000426

Initial Receipt: 7 August 2008

Acceptance: 19 October 2008

Publication: 3 April 2009

MS 307-209 
Figure F1. X-ray CT core measurements.

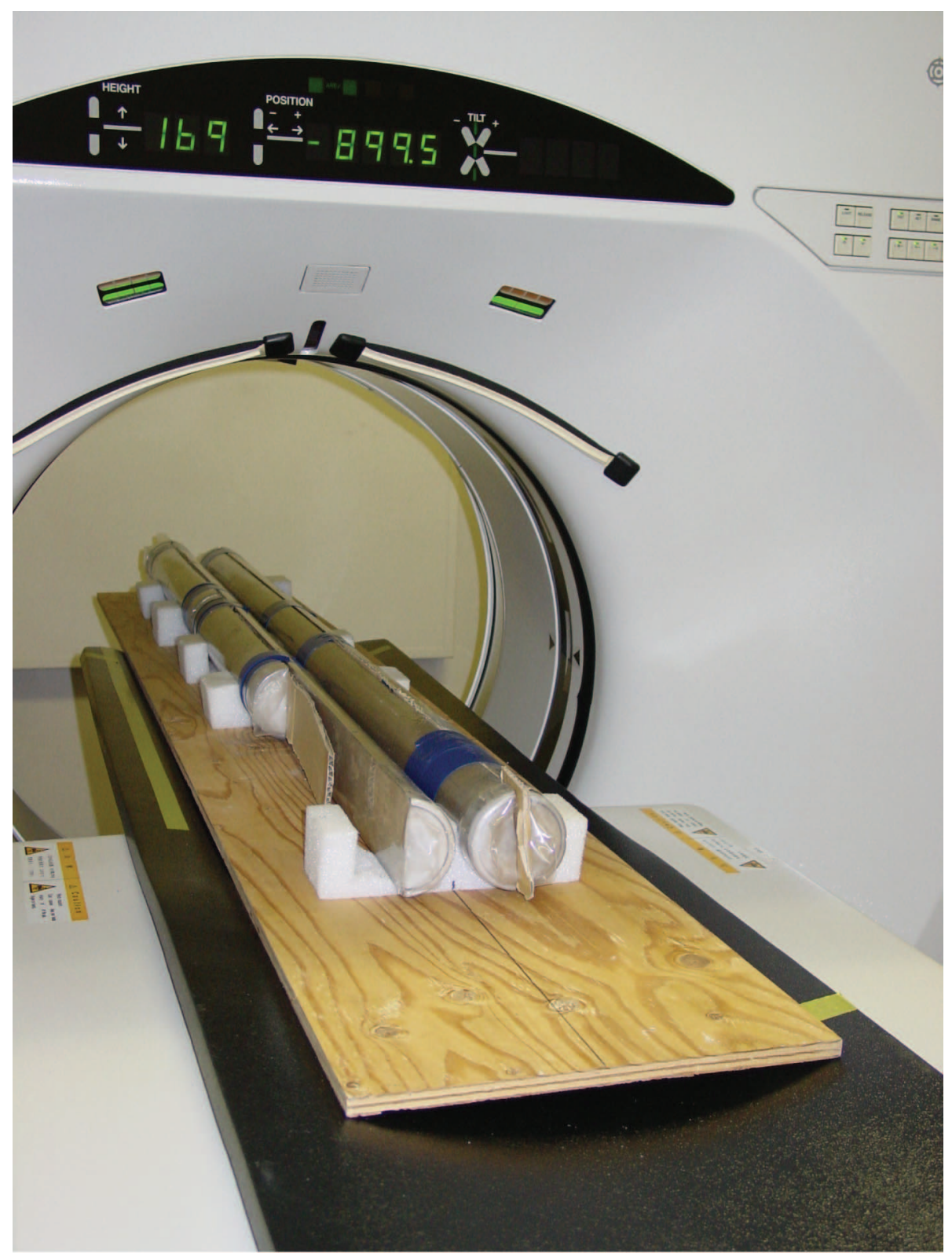


Figure F2. Enhanced raw data. Note that the board, which was used to mount core samples, is clearly imaged.

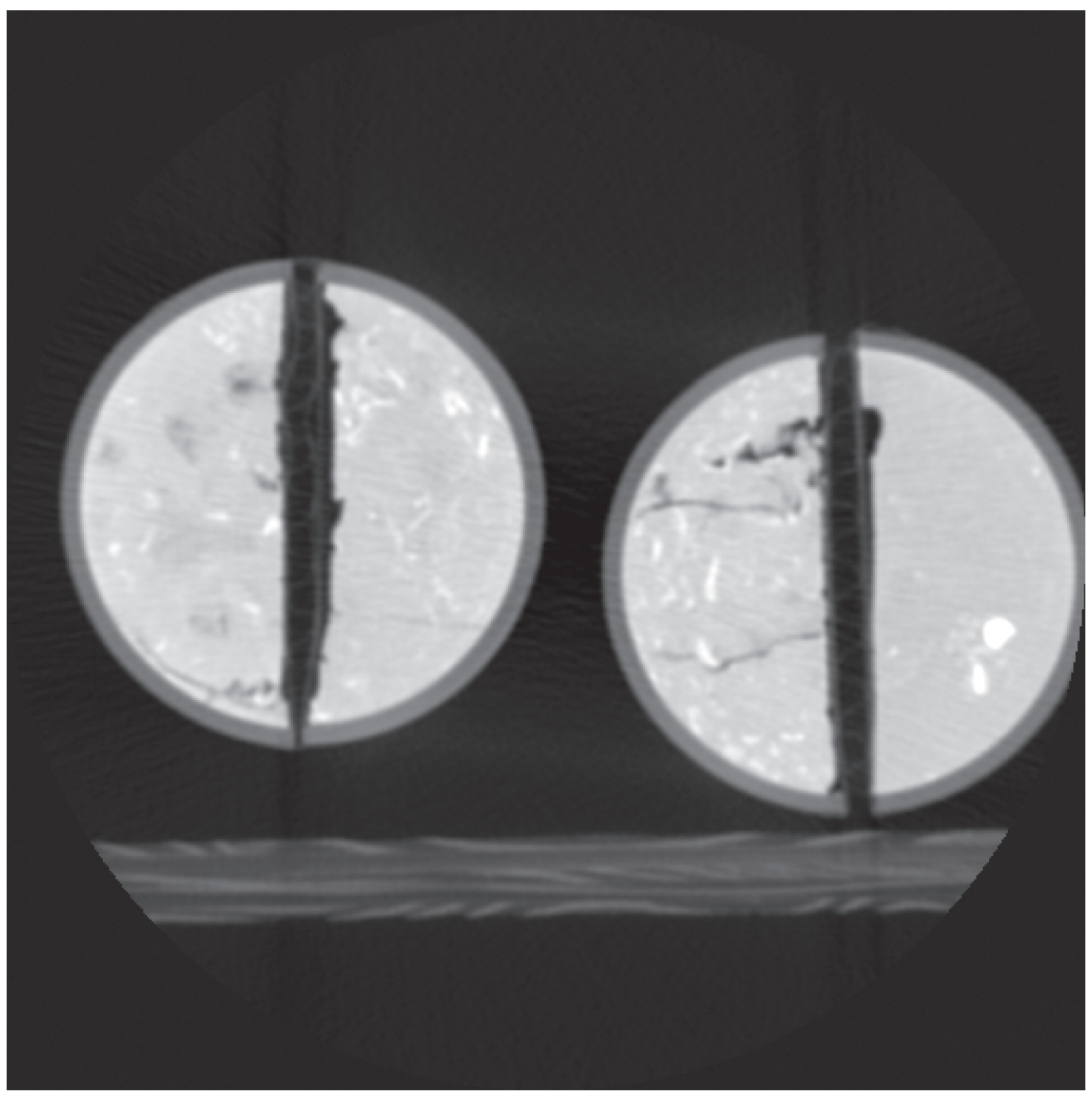


Figure F3. Example set of X-ray computerized tomography (CT) image slices of half-round cores from Section 307-U1316A-7H-1, 0-45.4 cm. Cuts of slices at every 8 intervals.

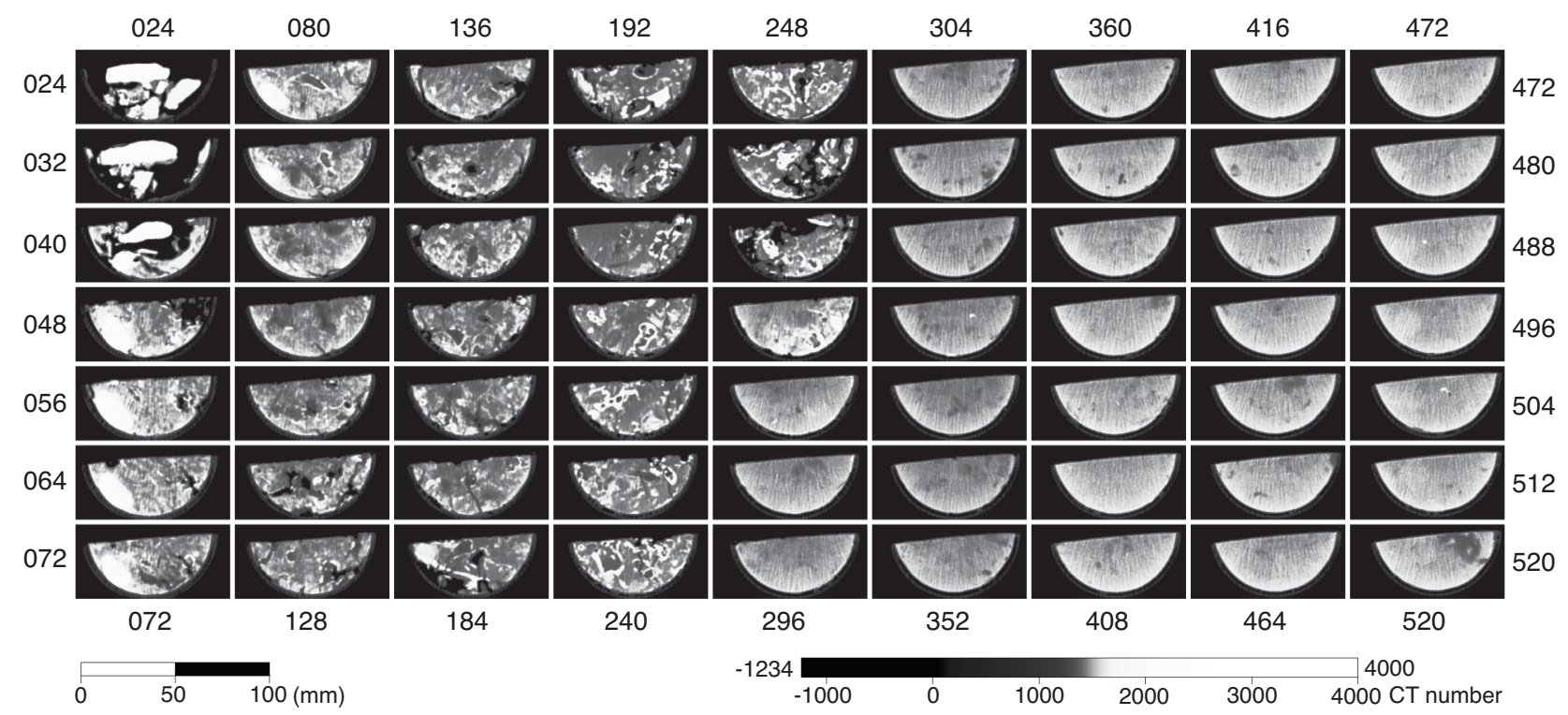


Figure F4. Histograms of CT number values for half-round cores, Hole U1316A. HU = Hounsfield units. A. Peaks around $-500,0$, and 1500 correspond to board, water, and cores, respectively. (Continued on next page.)

A
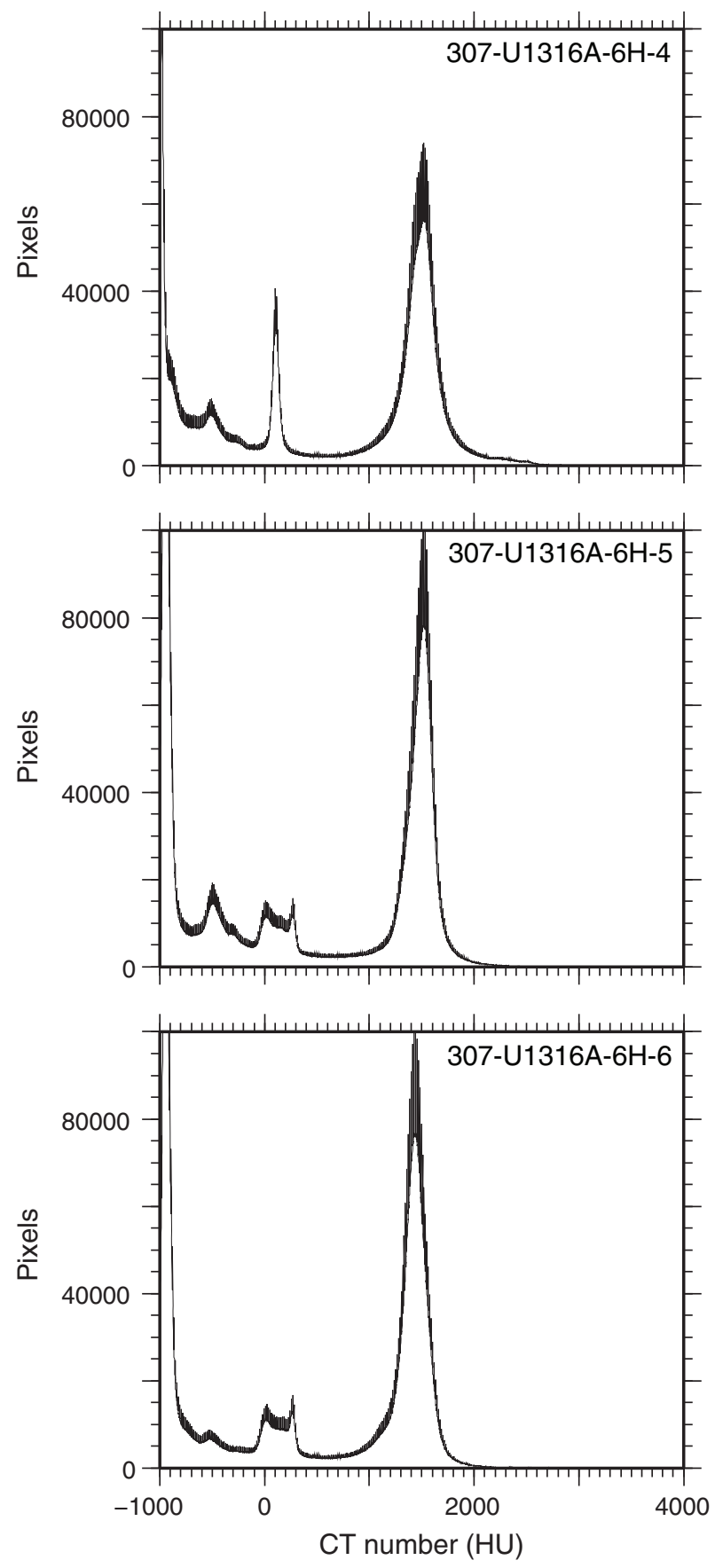
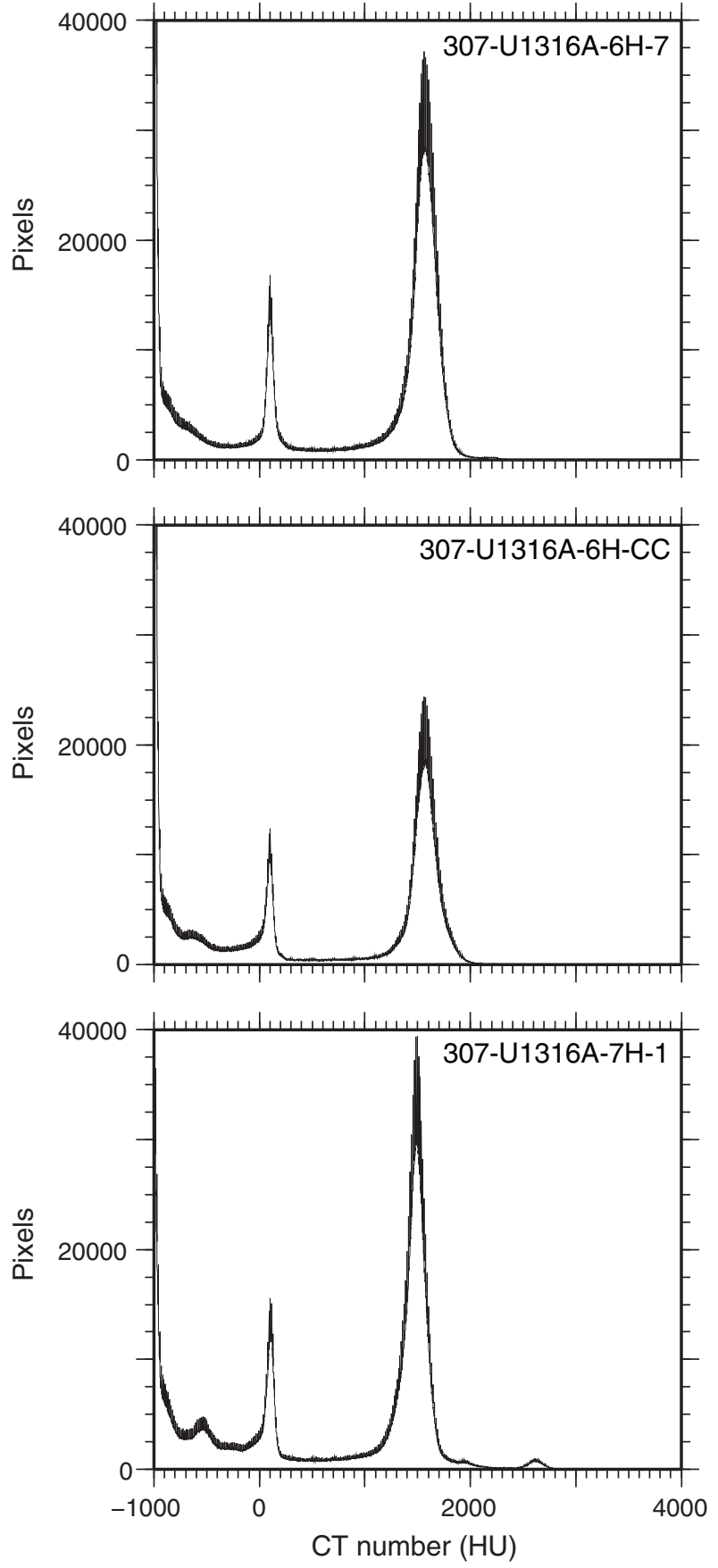
Figure F4 (continued). B. Histograms of CT number values $>2500$ show clear discriminations between dropstones/pebbles and host sediments. HU = Hounsfield units.

B
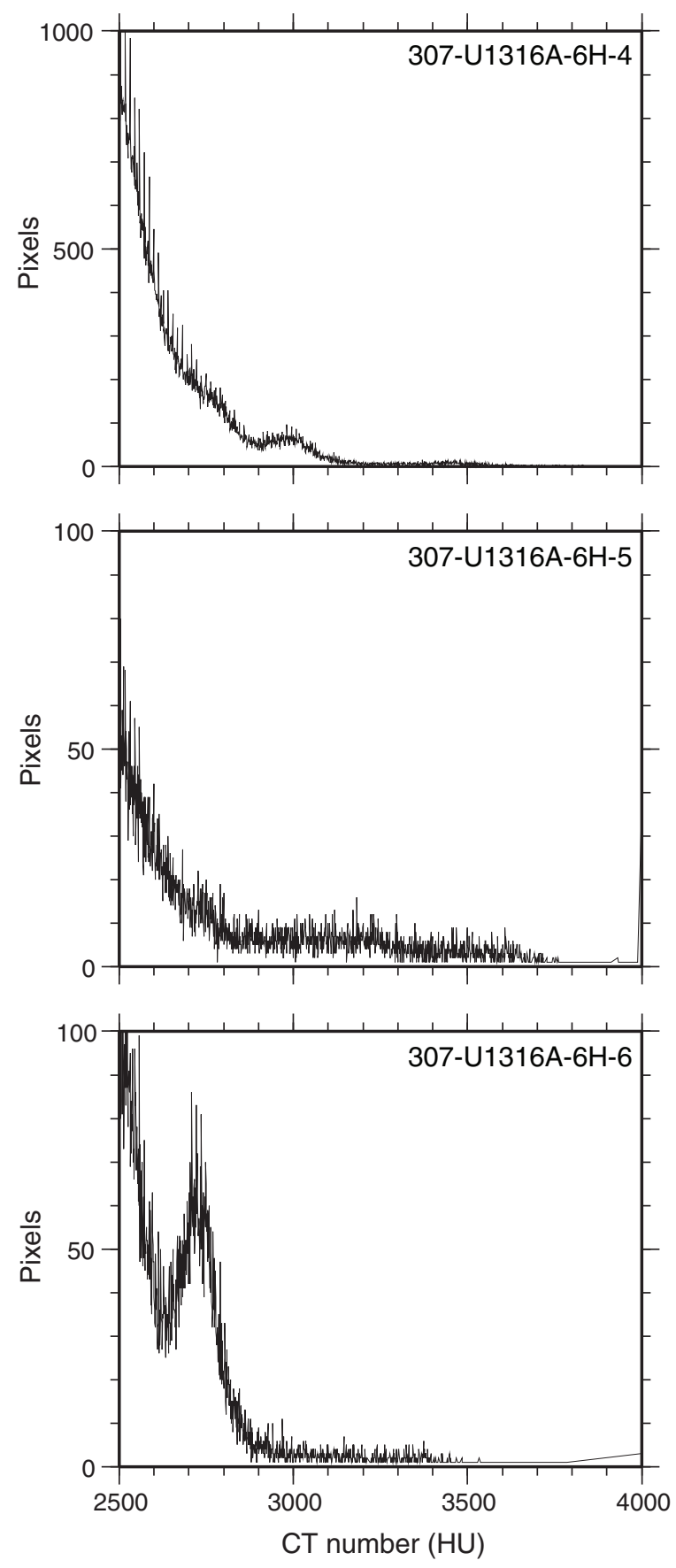
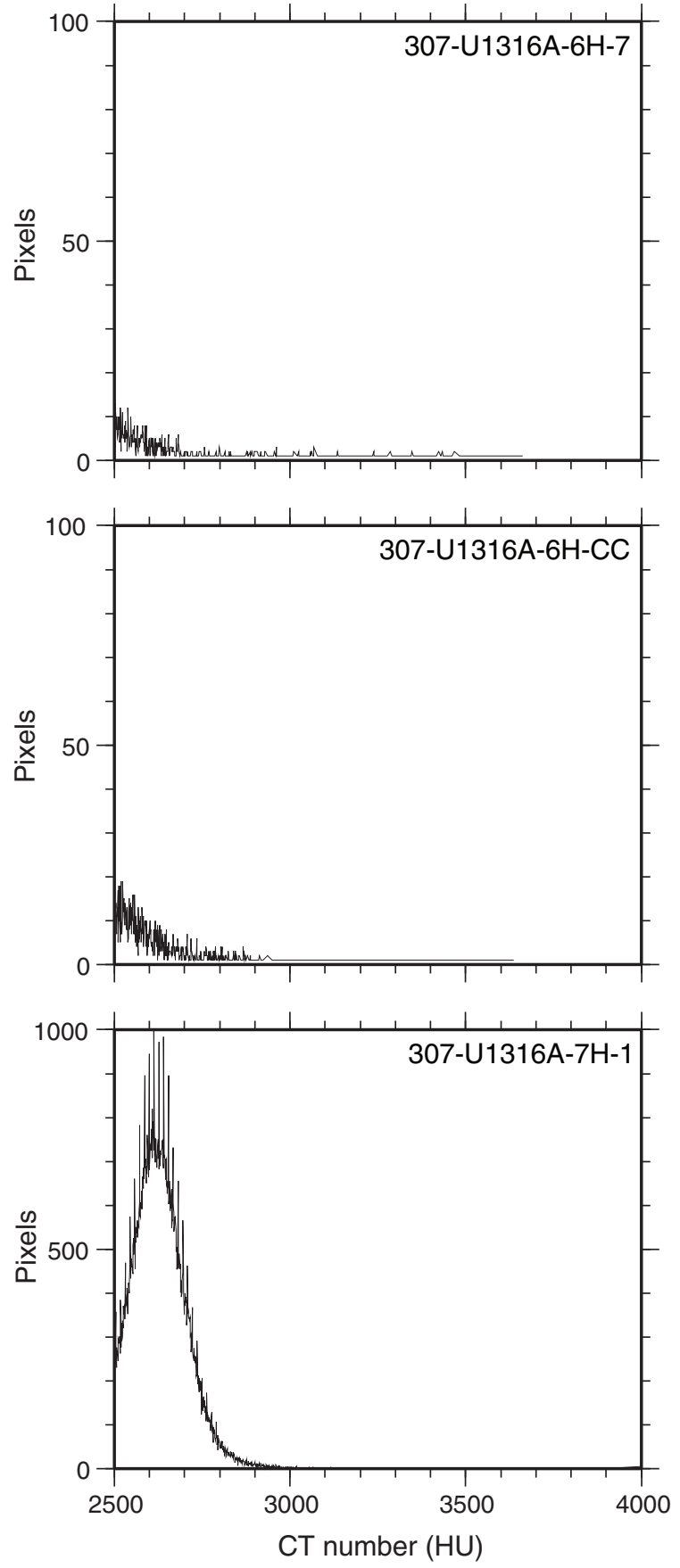
Figure F5. Geometry of X-ray CT image.

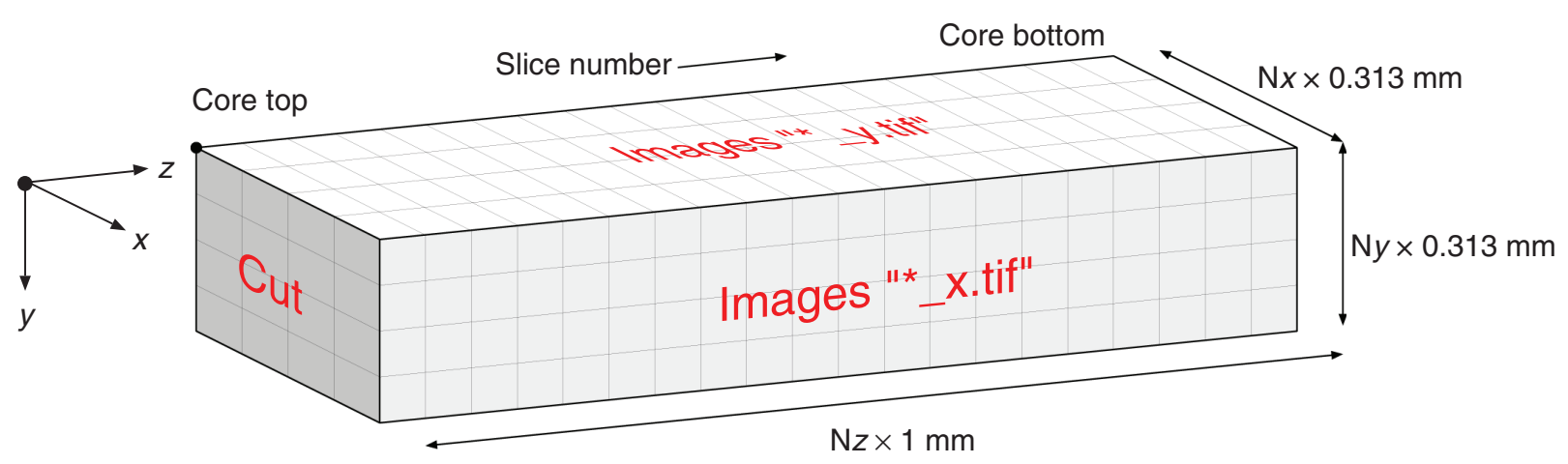


Figure F6. Cross section X-ray computerized tomography (CT) images, Section 307-U1316A-6H-4. Core top is to the left. Yellow dashed line = lithologic Subunit 2A/2B boundary. A. Every 12 intervals, $y-z$ plane, $0-99 \mathrm{~cm}$. (Continued on next two pages.)

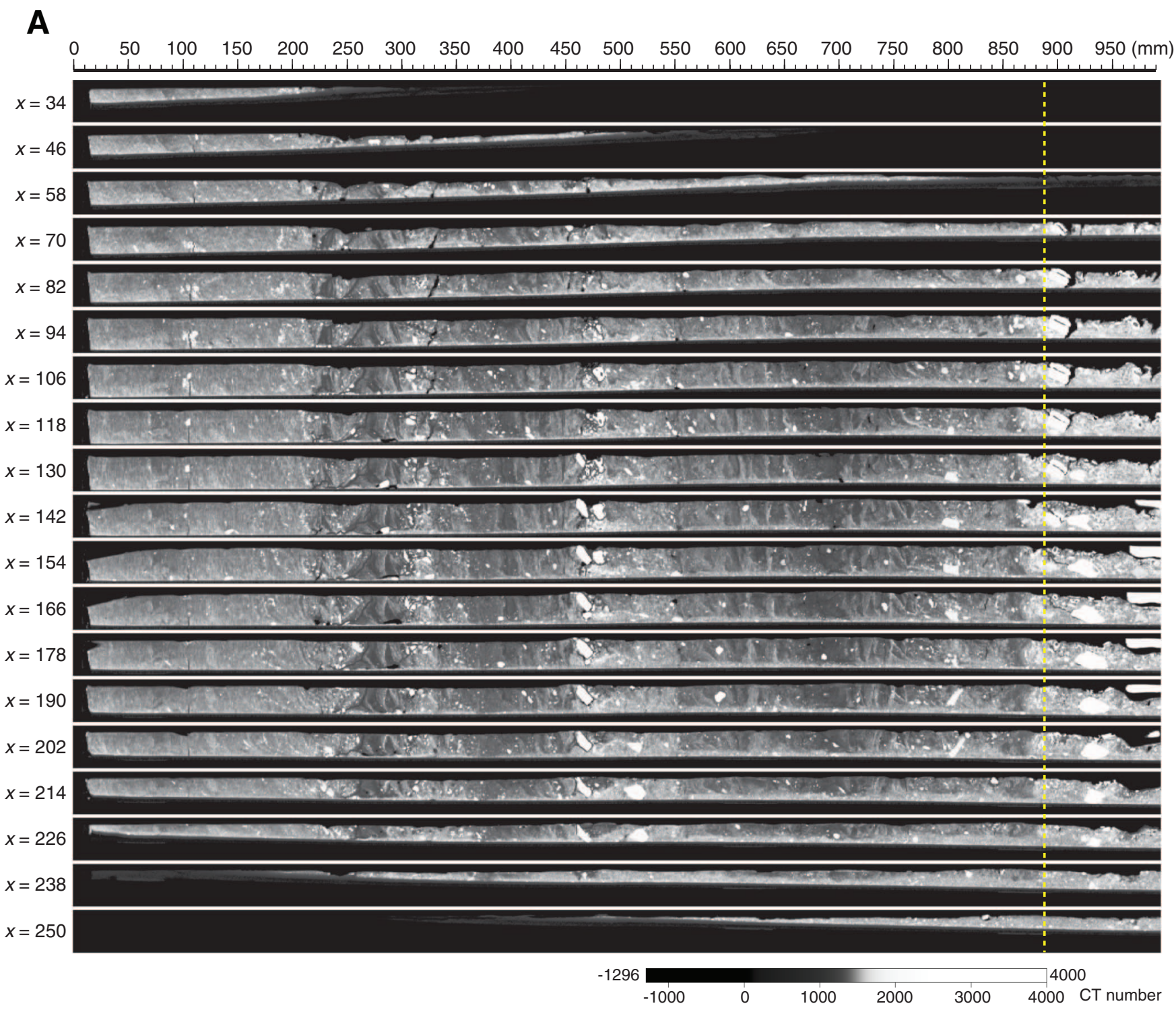


Figure F6 (continued). B. Every 14 intervals, $x-z$ plane, Section 307-U1316A-6H-4 $(0-99 \mathrm{~cm})$. CT = computerized tomography. (Continued on next page.)

B

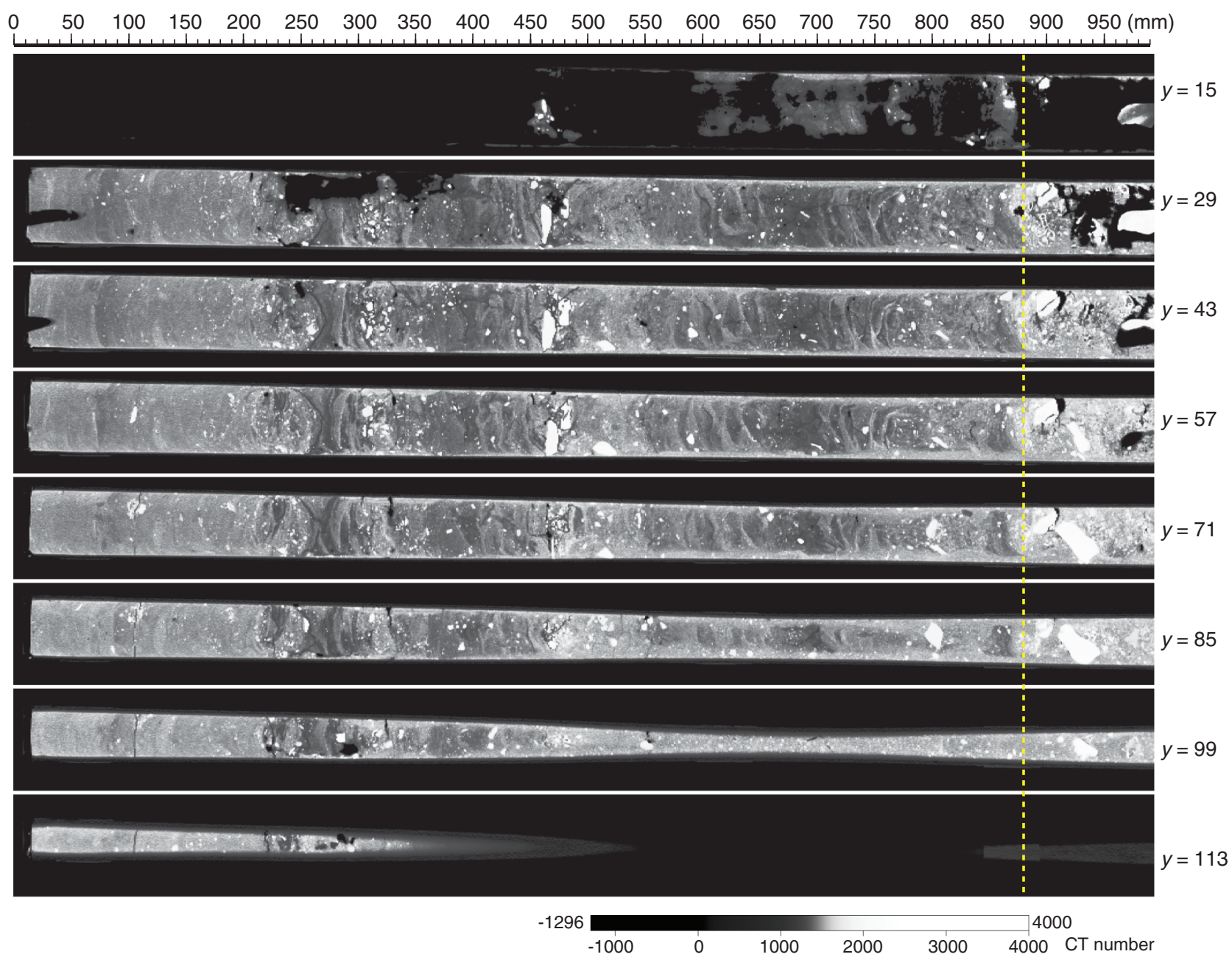


Figure F6 (continued). C. Every $14 \mathrm{~mm}$ interval, $y-z$ and $x-z$ planes, Section 307-U1316A-6H-4 $(0-99 \mathrm{~cm})$. CT $=$ computerized tomography.

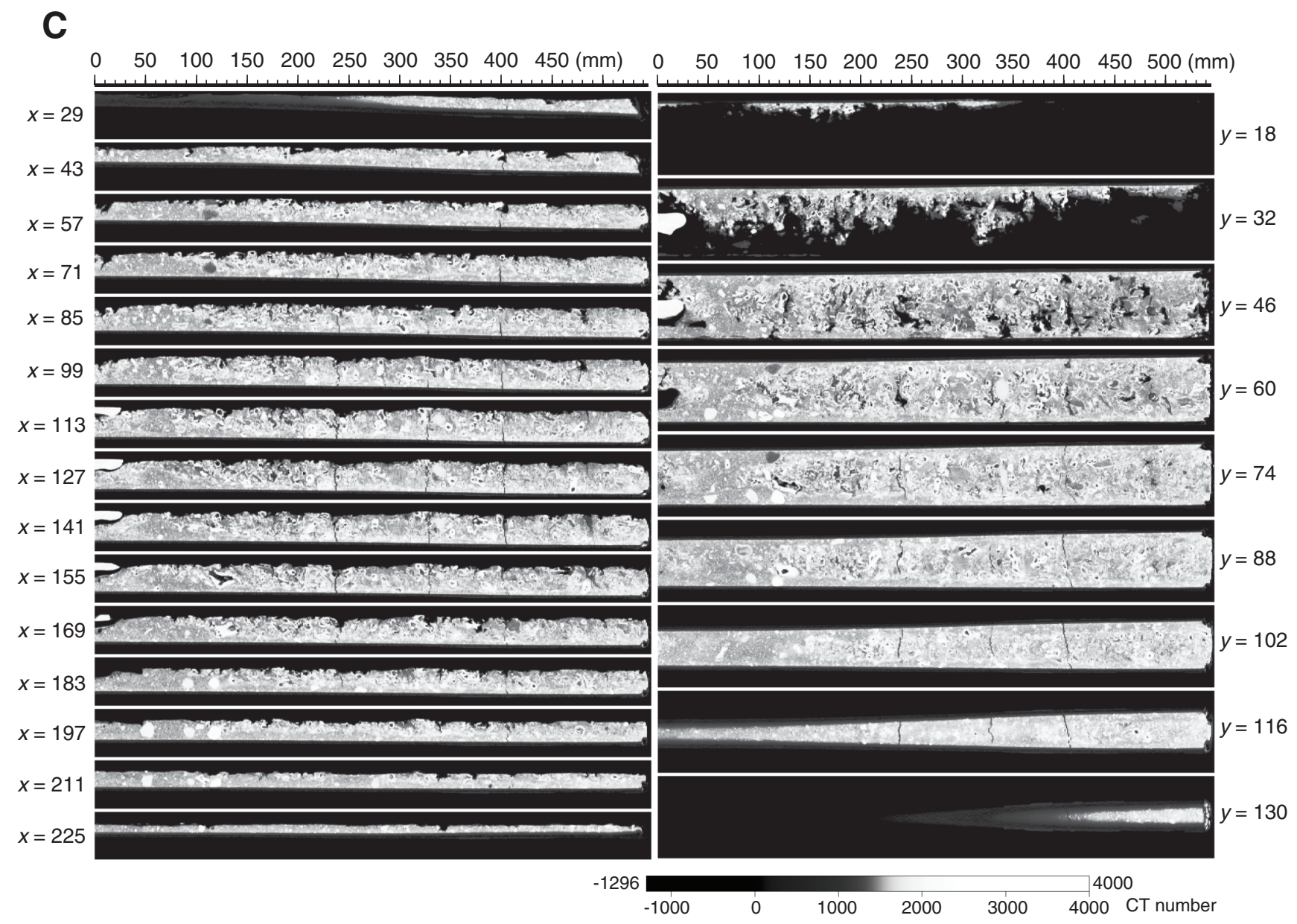


Figure F7. Cross section X-ray computerized tomography (CT) images, Section 307-U1316A-6H-5. A. Every 14 intervals, $y-z$ plane, $0-99 \mathrm{~cm}$. (Continued on next two pages.)

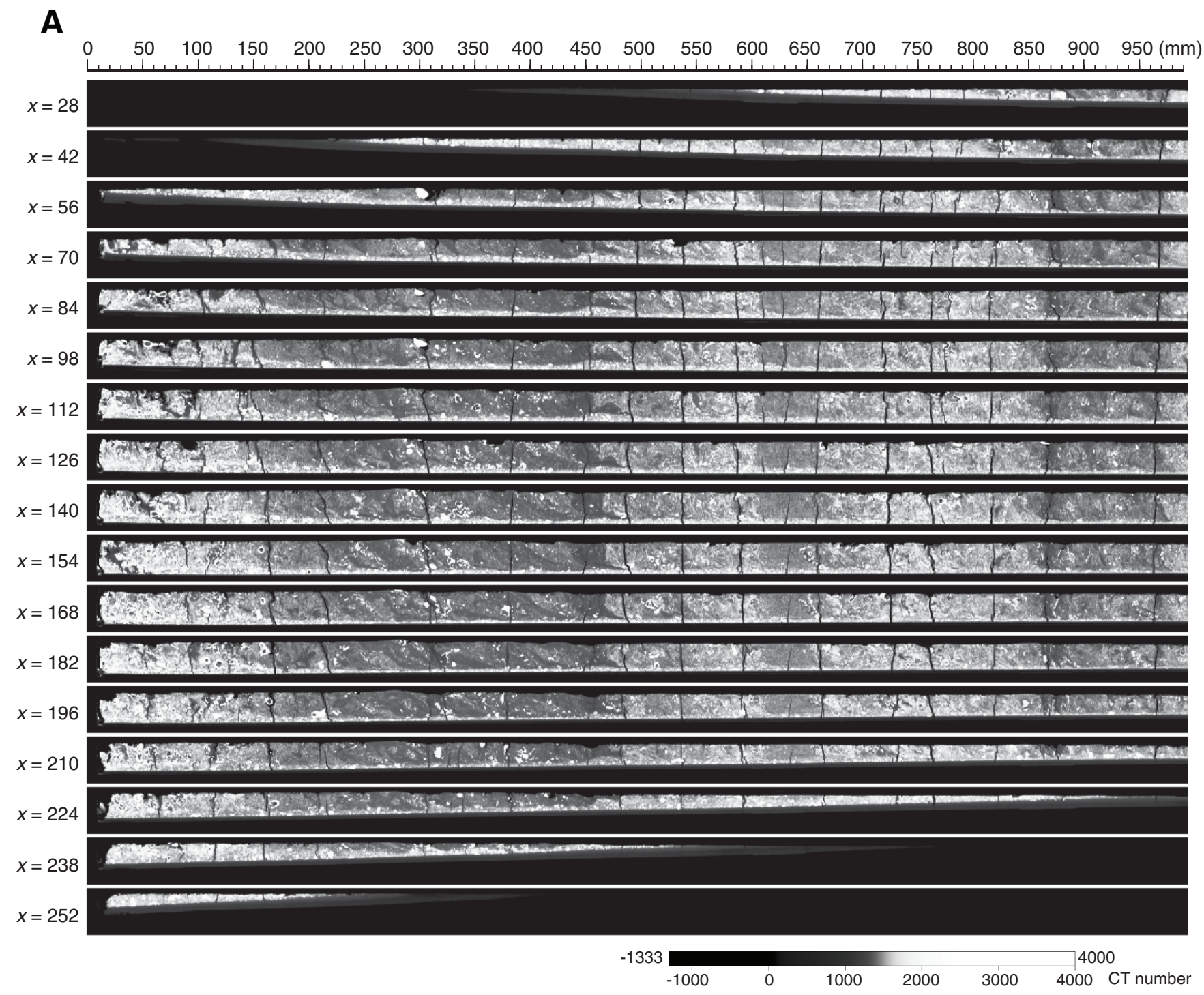


Figure F7 (continued). B. Every 13 intervals, $x-z$ plane, Section 307-U1316A-6H-5 $(0-99 \mathrm{~cm})$. CT = computerized tomography. (Continued on next page.)

B

$\begin{array}{llllllllllllllllllll}0 & 50 & 100 & 150 & 200 & 250 & 300 & 350 & 400 & 450 & 500 & 550 & 600 & 650 & 700 & 750 & 800 & 850 & 900 & 950 \\ (\mathrm{~mm})\end{array}$
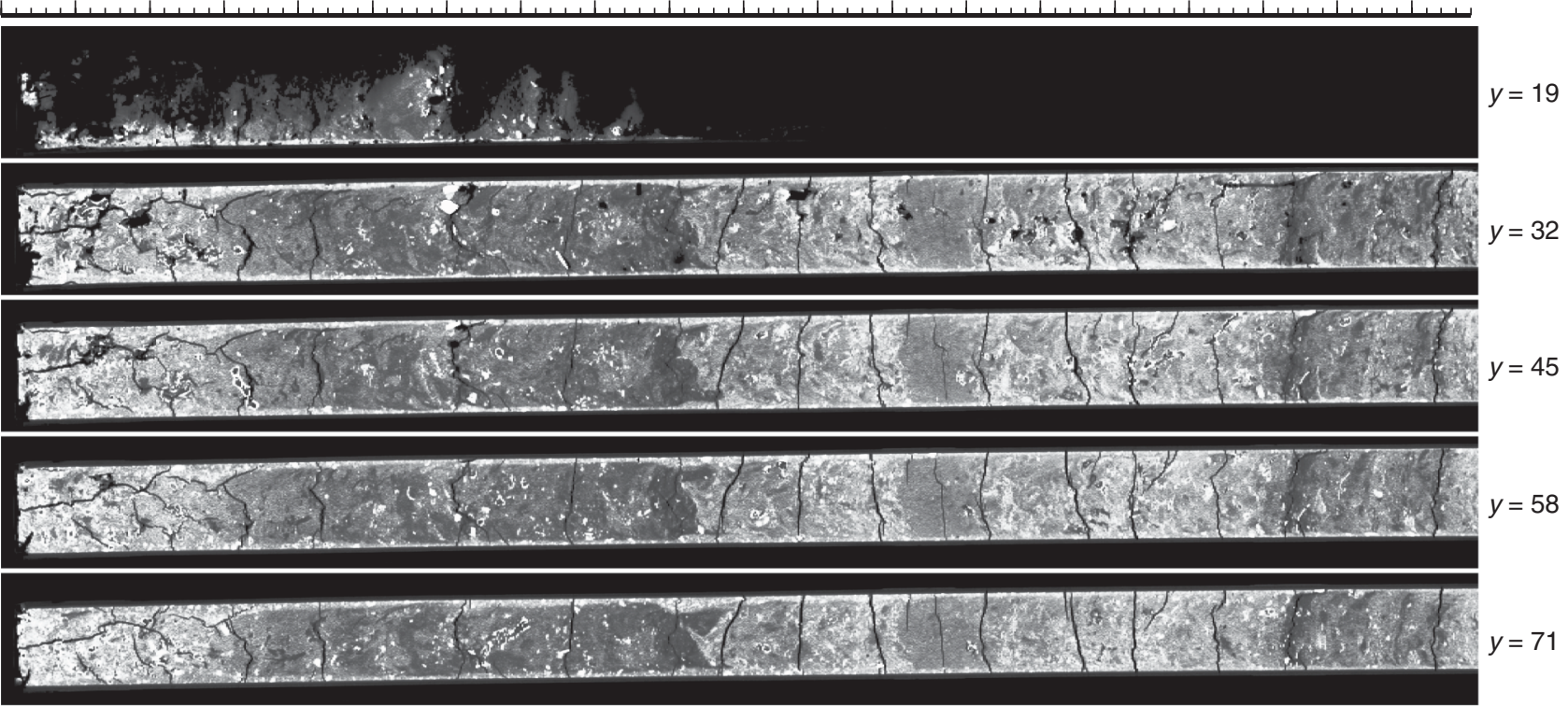

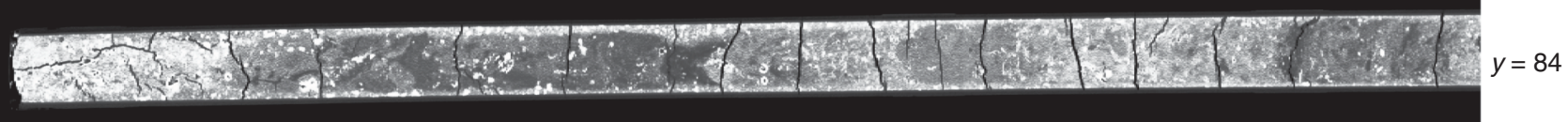

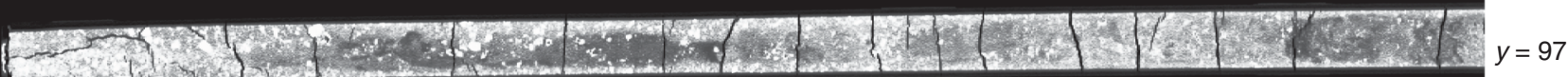

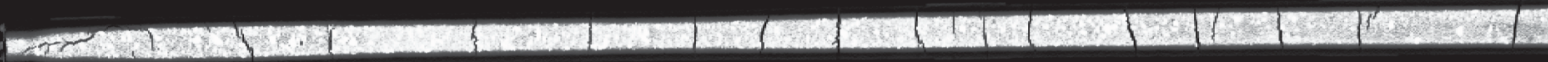

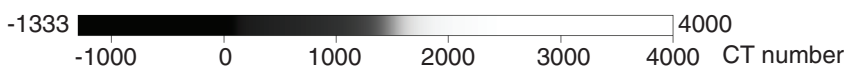


Figure F7 (continued). C. Every 14 and 13 intervals, $y-z$ and $x-z$ planes, Section 307-U1316A-6H-5 (0-99 cm). $\mathrm{CT}=$ computerized tomography.

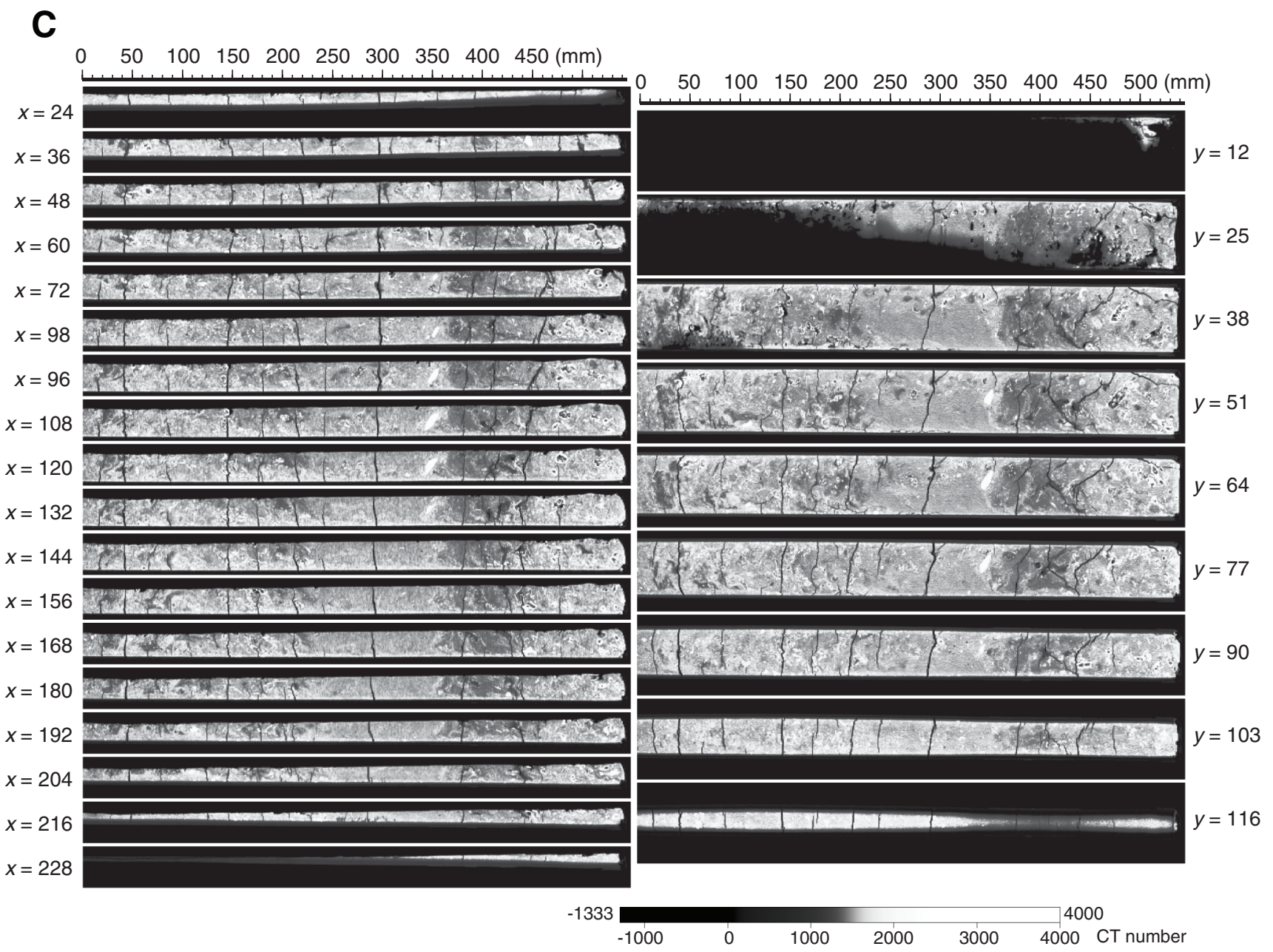


Figure F8. Cross section X-ray computerized tomography (CT) images, Section 307-U1316A-6H-6. A. Every 11 intervals, $y-z$ plane, $0-99 \mathrm{~cm}$. (Continued on next two pages.)

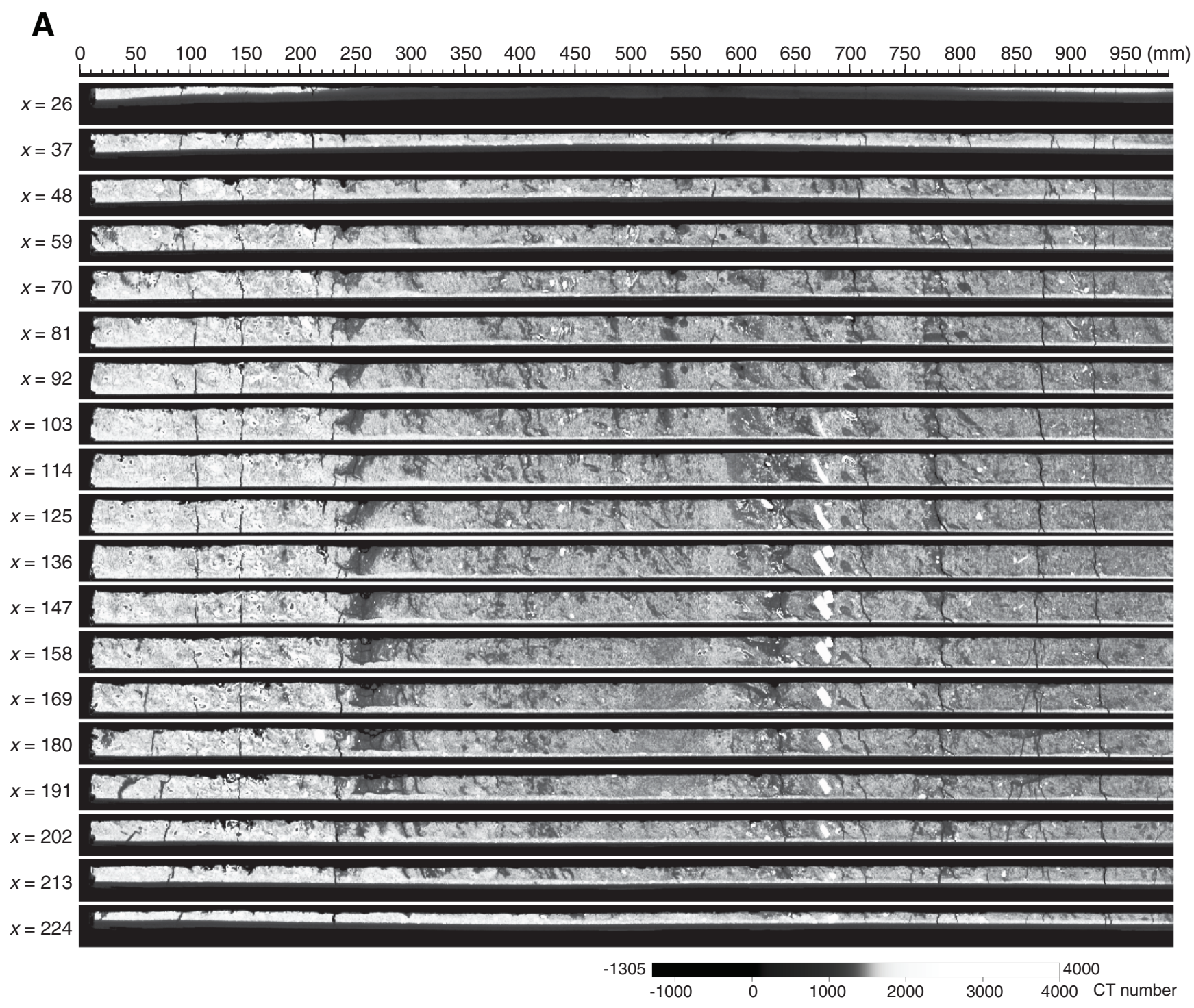


Figure F8 (continued). B. Every 11 intervals, $x-z$ plane, Section 307-U1316A-6H-6 $(0-99 \mathrm{~cm})$. CT = computerized tomography. (Continued on next page.)

\section{B}

$\begin{array}{llllllllllllllllllll}0 & 50 & 100 & 150 & 200 & 250 & 300 & 350 & 400 & 450 & 500 & 550 & 600 & 650 & 700 & 750 & 800 & 850 & 900 & 950(\mathrm{~mm})\end{array}$
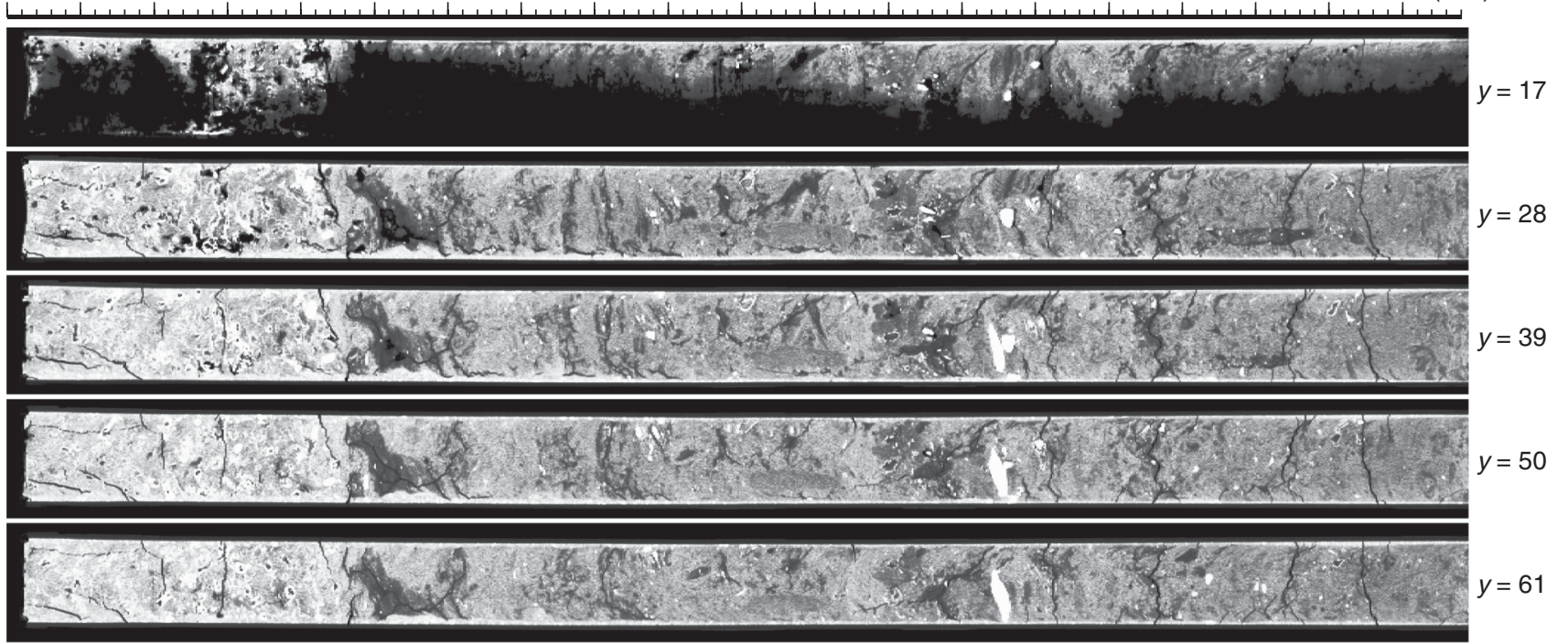

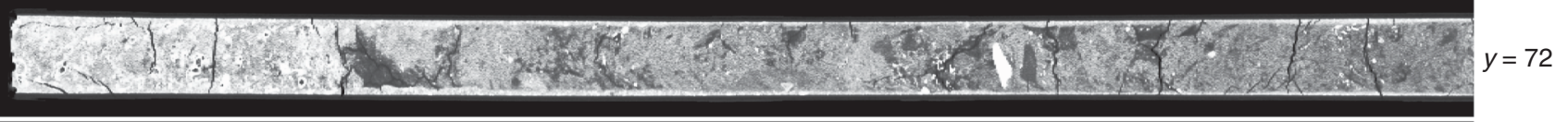

Cम

Carat
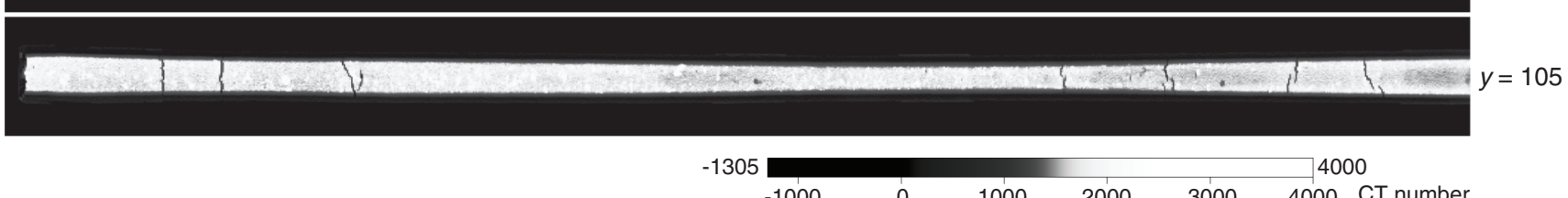

$\begin{array}{lllllll}-1000 & 0 & 1000 & 2000 & 3000 & 4000 & \text { CT number }\end{array}$ 
Figure F8 (continued). C. Every 13 and 12 intervals, $y-z$ and $x-z$ planes, Section 307-U1316A-6H-6 (0-99 cm). $\mathrm{CT}=$ computerized tomography.

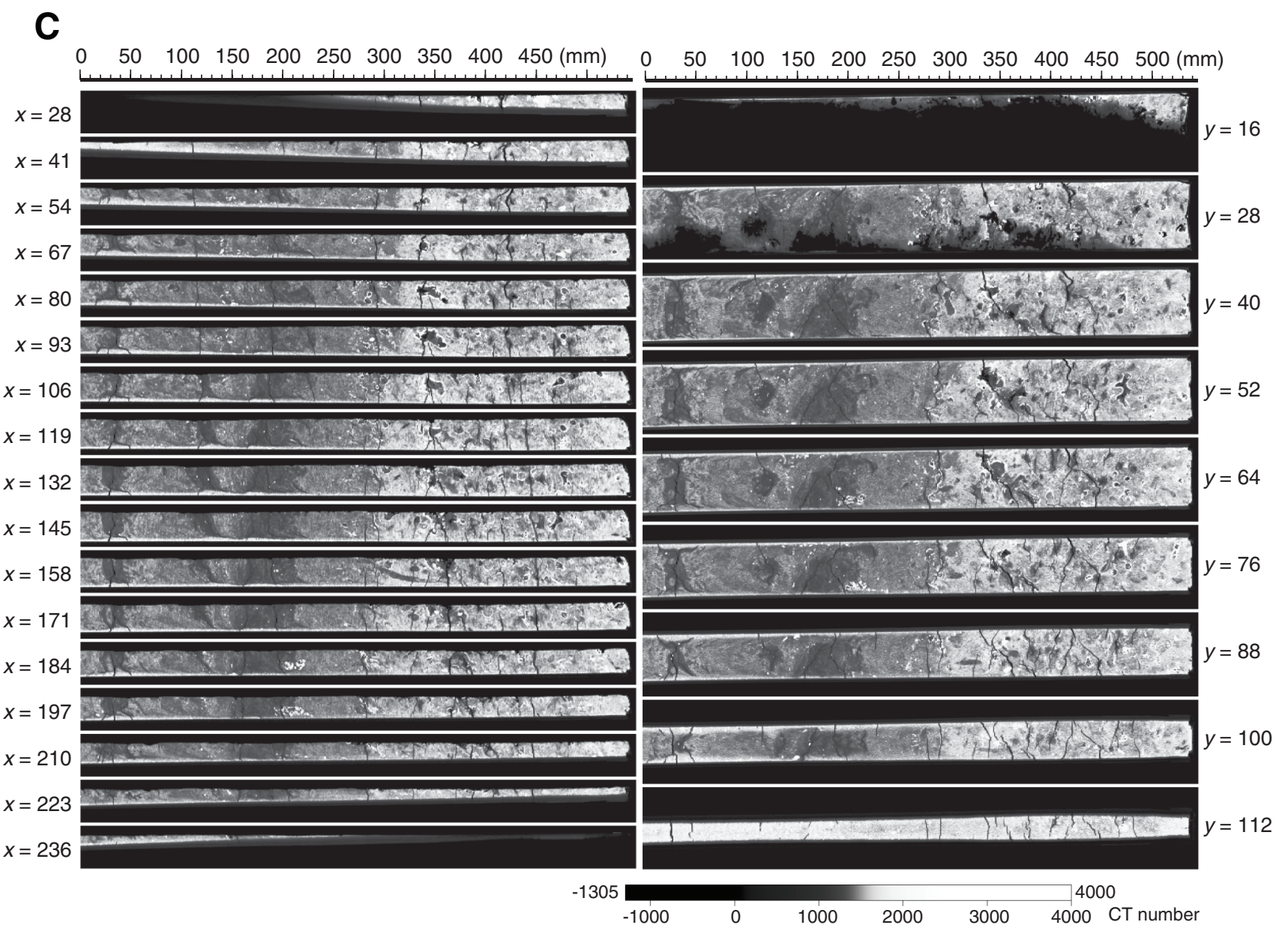


Figure F9. Cross section X-ray computerized tomography (CT) images on $y-z$ and $x-z$ planes, every 13 and 12 intervals, Section 307-U1316A-6H-7.

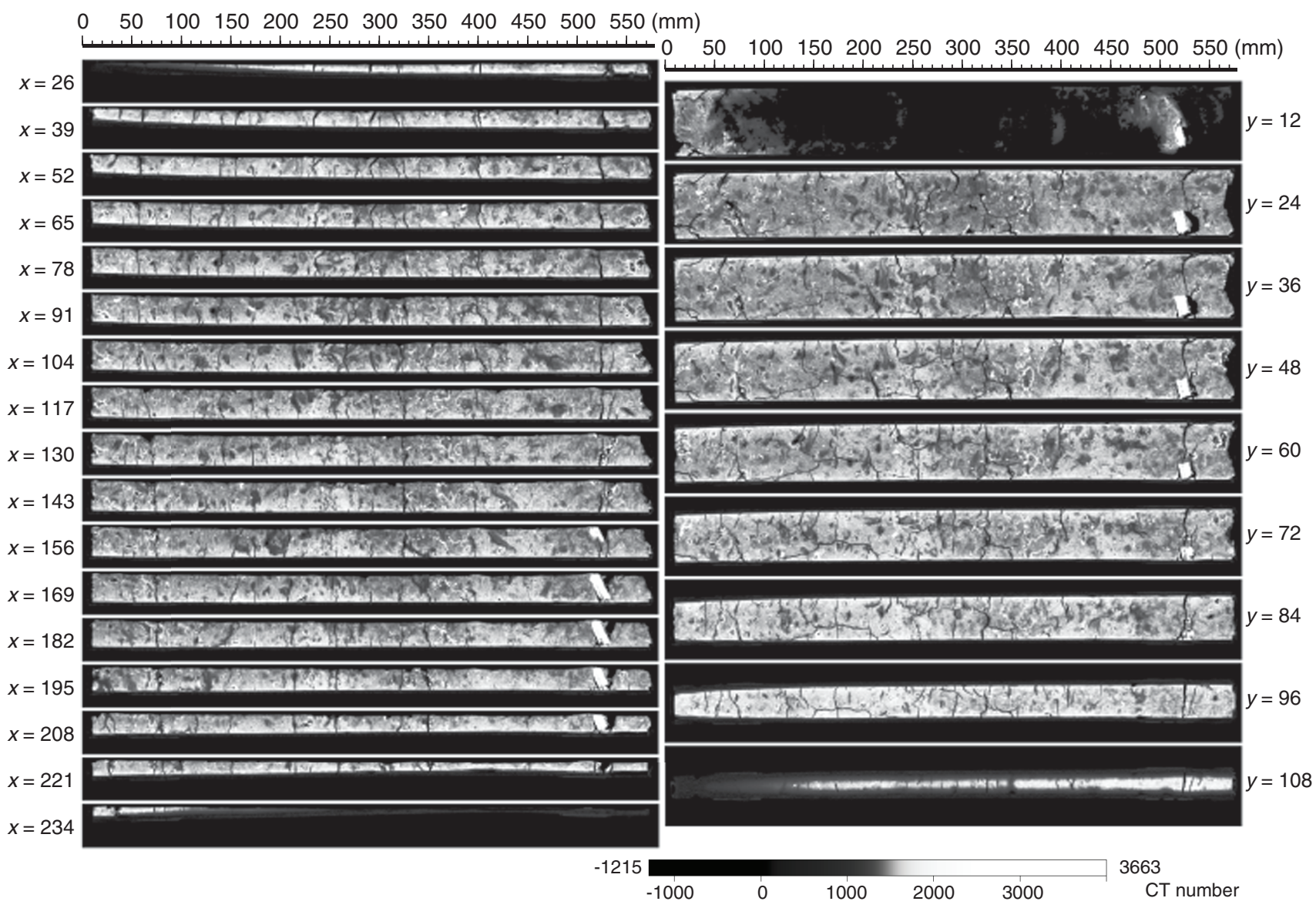


Figure F10. Cross section X-ray computerized tomography (CT) images on $y-z$ and $x-z$ planes, every 12 and 11 intervals, Section 307-U1316A-6H-CC.

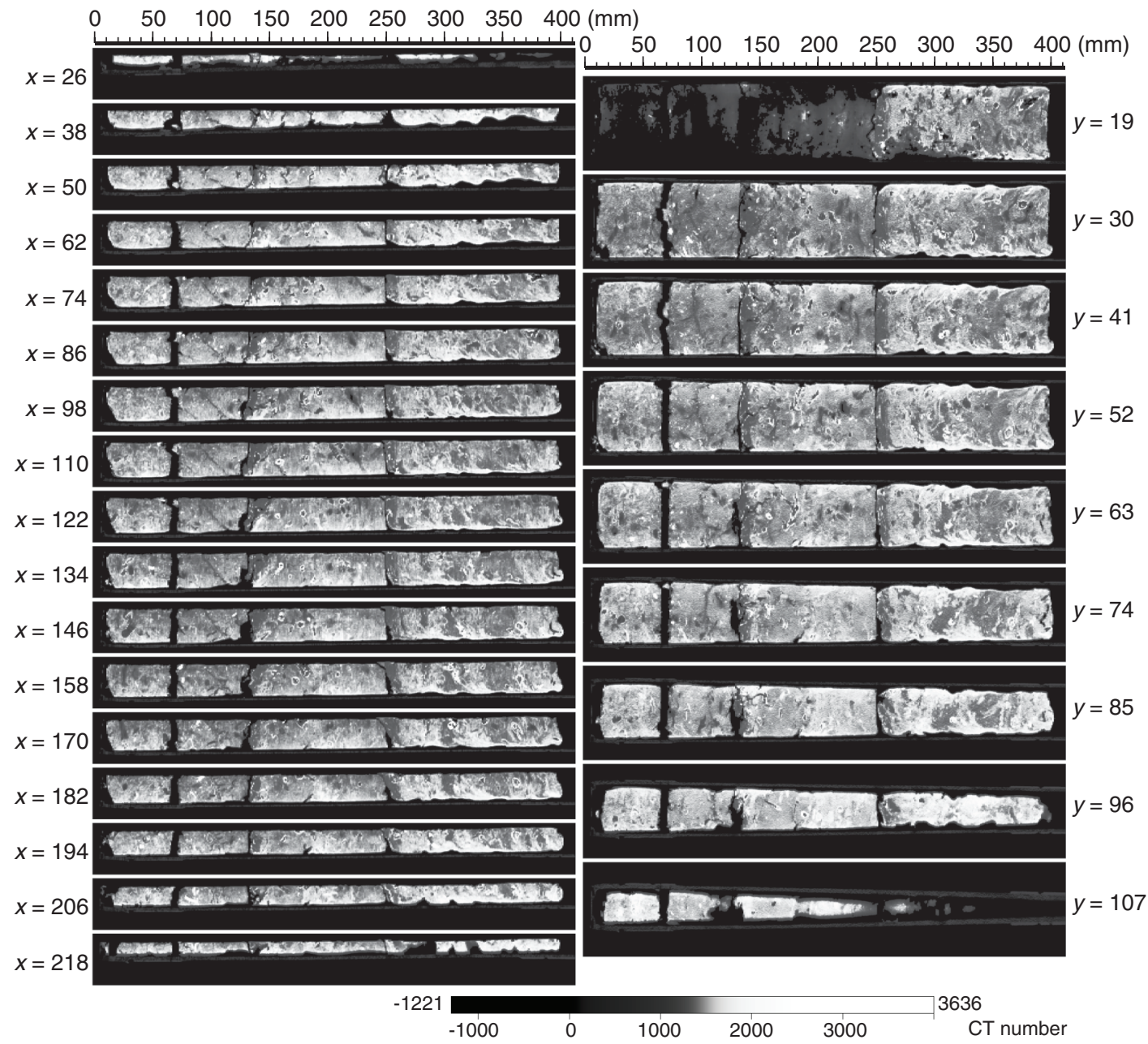


Figure F11. Cross section X-ray computerized tomography (CT) images on $y-z$ and $x-z$ planes, every 13 and 12 intervals, Section 307-U1316A-7H-1.

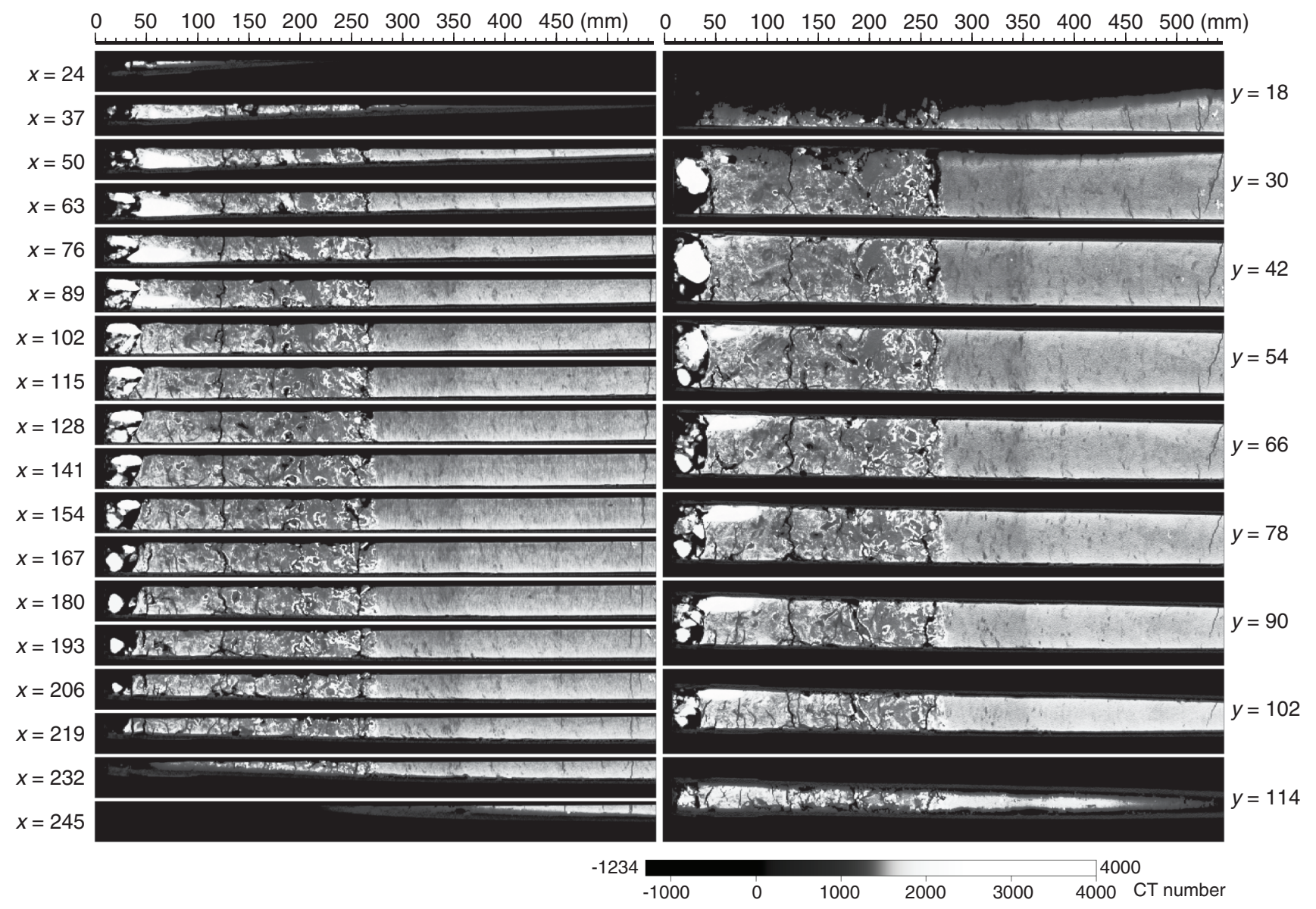


Figure F12. Animated illustration of three-dimensional distribution of CT numbers, Section 307-U1316A-7H1. Lower right number shows threshold level of CT numbers ranging from 30 to 245 every 5 . This core sample is $62 \mathrm{~mm}$ in diameter and $545 \mathrm{~mm}$ in length. (Windows and Macintosh users: view QuickTime movie. UNIX users: view animated GIF in Web browser.)

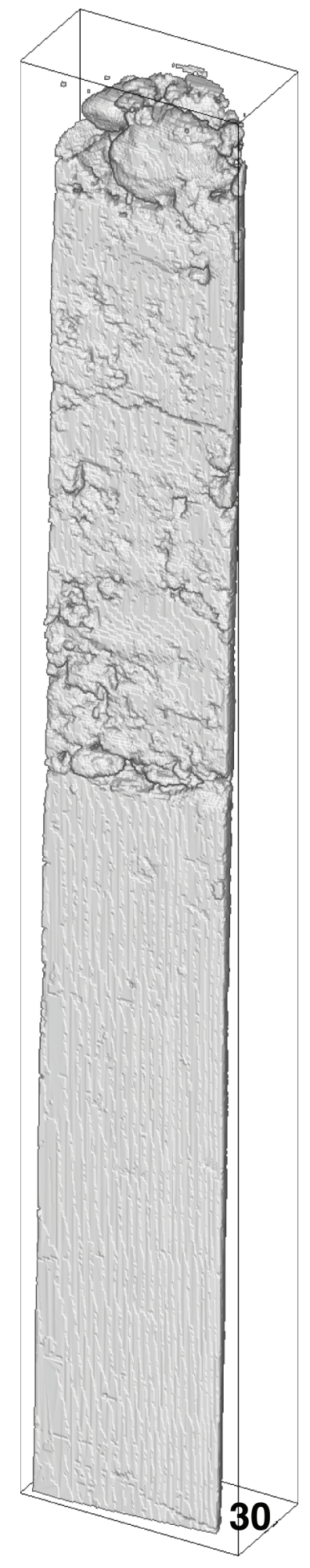


Figure F13. Magnetic susceptibility (crosses) and GRA gamma density (inverted triangles) for the same sections used for X-ray CT measurements.

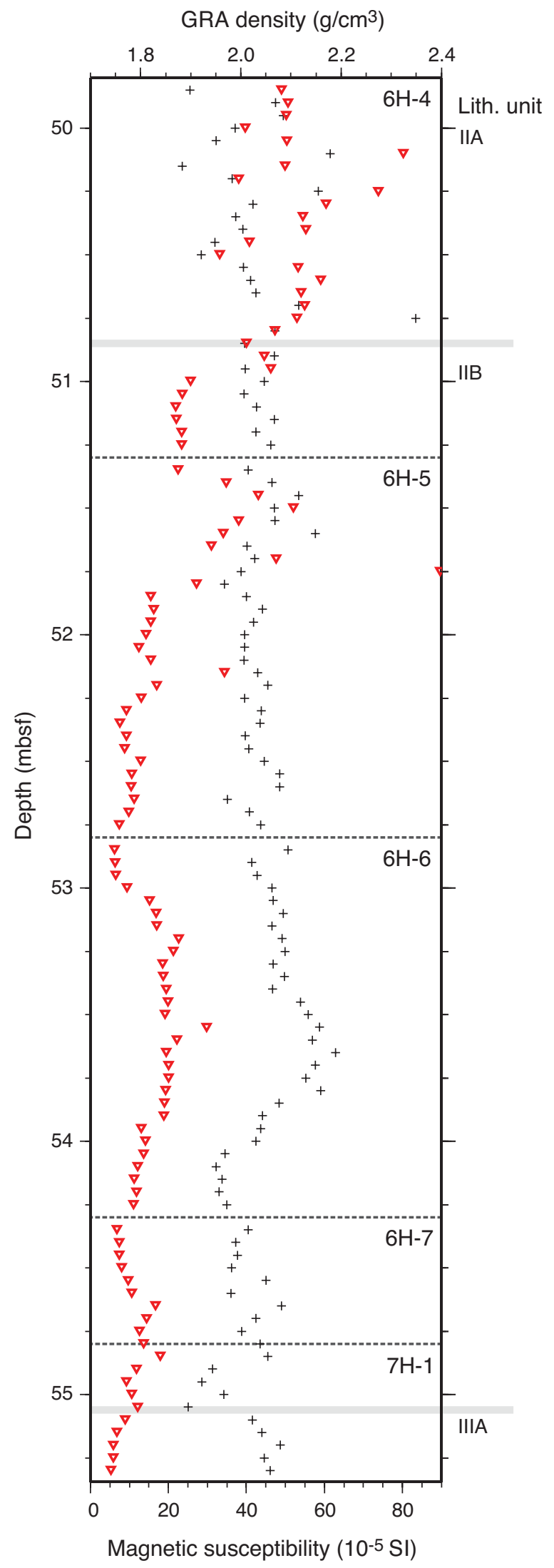

